\title{
RELIGIÃO, ESPIRITUALIDADE E TRANSPLANTES: UMA REVISÃO INTEGRATIVA DA LITERATURA
}

\author{
Religion, spirituality and transplantation: an integrative literature review
}

Mariana de Siqueira Rosa, Ana Márcia Chiaradia Mendes - Castillo

\section{RESUMO}

Objetivo: Investigar a produção científica quanto à religião e espiritualidade no contexto dos transplantes de órgãos sólidos. Método: Revisão integrativa da literatura realizada nas bases de dados MEDLINE, LILACS, PUBMED, na biblioteca Scielo e no Journal of Religion and Health, por artigos primários publicados em português, inglês ou espanhol. Os dados foram coletados por meio de instrumento de fichamento e analisados de forma qualitativa. Resultados: foram selecionados 12 artigos, descritos em três categorias: vivências e perspectivas espirituais sobre o processo de doação e transplante de órgãos; influência da religião e espiritualidade na tomada de decisão diante do processo doação e transplante; religião/espiritualidade influenciando o paciente/cuidador na doença e no transplante. Conclusão: A literatura disponível tem indicado que a religião e espiritualidade são fatores que influenciam de múltiplas maneiras os pacientes nesse contexto, e demandam maiores investigações.

Descritores: Transplantes; Doadores de Tecidos; Religião; Espiritualidade.

Instituições:

Faculdade de Enfermagem. Universidade Estadual de Campinas - Campinas/SP, Brasil.

\section{Correspondence:}

Mariana de Siqueira Rosa

E-mail: mariana_siqueirarosa@hotmail.com

https://doi.org/10.53855/bjt.v24i2.013

\section{INTRODUÇÃO}

A realização de transplantes consiste em um avanço significativo da ciência, do Sistema de Saúde e de toda sociedade brasileira. $O$ transplante de órgão sólido é uma opção de tratamento para melhorar a qualidade de vida de pessoas que apresentem doença de rim, pâncreas, fígado, coração, pulmão e intestino, de natureza crônica e de caráter irreversível e em estágio final. $^{1}$

Embora haja crescimento da taxa efetiva do número de transplantes, o número de órgãos disponíveis não é capaz de suprir a demanda. Estima-se que até 100 pacientes por ano em cada milhão de habitantes desenvolvam morte encefálica, em consequência de acidentes ou de hemorragia intracerebral, indicador que revela grande número de doadores potenciais de órgãos 
em todas as populações. Porém, a realidade com que nos deparamos é a de que em países desenvolvidos, consegue-se obter de 20 a 40 doadores por milhão de habitantes por ano, e países próximos ao Brasil, como Argentina e Chile, alcançam uma taxa de 10 a 12 doadores por milhão de habitantes por ano. ${ }^{2}$ Essa baixa oferta de órgãos caracteriza-se como um dos maiores obstáculos enfrentados pelas equipes transplantadoras em todos os países, pois o aumento da demanda por transplantes em escala maior que a efetivação de doações resulta na ampliação das filas de espera. ${ }^{3}$

O tempo de espera para receber o transplante pode ultrapassar um ano e atingir até nove anos para fígado, e mais de 11 para o rim. $^{4}$ Essa longa espera pode gerar sofrimento psíquico para o paciente que está na fila e também para sua família, além de ocasionar aproveitamento de órgãos de qualidade inferior, com consequente menor duração dos enxertos, necessidade de retransplantes e provável elevação nos índices de mortalidade pós-transplante. ${ }^{4}$

Frente a essas inúmeras questões, os pacientes que estão na espera por um transplante enfrentam sentimentos como tristeza pela doença, sofrimento, revolta, sentimentos de fragilidade e ansiedade; sentimentos negativos relacionados às múltiplas mudanças ocorridas na vida, tais como: inutilidade, impotência, desconforto, perda, desilusão, vergonha, insatisfação e labilidade emocional. ${ }^{5}$

Para lidar com esses múltiplos sentimentos, os indivíduos utilizam recursos de enfrentamento, que funcionam como mecanismos de ajustamento e suporte e auxiliam na elaboração de estratégias de enfrentamento. Dentre os recursos utilizados, nota-se a importância da família, da equipe de saúde e da religiosidade. ${ }^{5}$

É sabido que a dimensão religiosa e espiritual tem significado importante na vida do ser humano, principalmente quando há iminência de doenças, ${ }^{5}$ pois pode contribuir para o alívio do sofrimento e maior esperança em relação à qualidade de vida.

Embora distintas, a religião e a espiritualidade estão intimamente imbricadas, uma vez que a espiritualidade é considerada a essência de uma pessoa, como uma busca de significado e propósito de vida, enquanto a religiosidade é a expressão da própria espiritualidade, através de rituais, dogmas e doutrinas. ${ }^{6-7}$

Na última década, atenção maior tem sido dispensada à espiritualidade e seu papel como estratégia de enfrentamento utilizada por pacientes com câncer; afinal, a espiritualidade e também a religião mostramse importantes no enfrentamento de tal doença, ao desempenhar papel protetor contra a morbidade psicológica, pois têm impacto importante sobre a maneira como a pessoa lida com a enfermidade; ${ }^{8-9}$ outros estudos também apontam o uso da religião e espiritualidade como fator de melhora da qualidade de vida de idosos e de pacientes com algumas doenças crônicas, como Hipertensão Arterial Sistêmica. ${ }^{10-12}$ Mas a relação entre o uso da religião e espiritualidade por pacientes vivenciando doação e transplante de órgãos é pouco abordada.

Acredita-se que acessar o conhecimento já disponível na literatura científica - acerca da religião e espiritualidade no contexto dos transplantes - trará esclarecimentos sobre o que se tem produzido sobre o assunto até o momento, além de levantar subsídios para novas investigações, de maneira a reunir e consolidar o conhecimento, bem como identificar lacunas e propor perspectivas para novos estudos. Diante disso, o objetivo deste estudo é investigar a produção científica quanto à religião e espiritualidade no contexto dos transplantes de órgãos sólidos.

\section{MÉTODOS}

Trata-se de um estudo de revisão integrativa da literatura, norteado pela questão: o que se tem publicado, na última década, acerca da religião e espiritualidade relacionadas a pacientes e famílias no contexto dos transplantes de órgãos sólidos?

As bases de dados selecionadas para busca de artigos foram a LILACS (Literatura Latino-Americana e do Caribe em Ciências da Saúde), a biblioteca Scielo, PUBMED e MEDLINE. Além dessas, também consideramos as publicações do Journal of Religion and Health, periódico de referência para o tema de estudo.

Os descritores das Ciências da Saúde (DeCs) utilizados na busca foram transplants $A N D$ religion AND/OR spirituality. Como critérios de inclusão, foram considerados artigos primários, publicados em inglês ou português nos últimos 10 anos, em periódicos das áreas de ciências da saúde e humanidades, com tema relacionado a transplantes, religião e espiritualidade. Foram excluídos artigos que tratassem de transplantes de medula óssea e de células tronco.

A busca e seleção dos artigos foi realizada entre os meses de janeiro a maio de 2020. Foram encontrados dois artigos na LILACS, cinco na biblioteca Scielo, 78 na PUBMED, 20 na MEDLINE e oito no Journal of Religion and Health, resultando um total de 113 artigos. A partir da leitura dos títulos e resumos, foram selecionados aqueles que permitiram relacioná-los à pergunta original do estudo, restando 16 após exclusão das duplicatas. Após leitura cuidadosa dos resumos, 
quatro artigos foram excluídos por não apresentarem relação da religião/espiritualidade e transplantes. Cabe ressaltar que todo o processo de seleção e triagem dos artigos foi feita por pares. A figura 1 ilustra o fluxograma PRISMA, percurso validado para triagem e seleção de artigos para estudos de revisão, aplicado ao trabalho.

Figura 1 - Descrição da seleção dos artigos. Campinas, 2020.
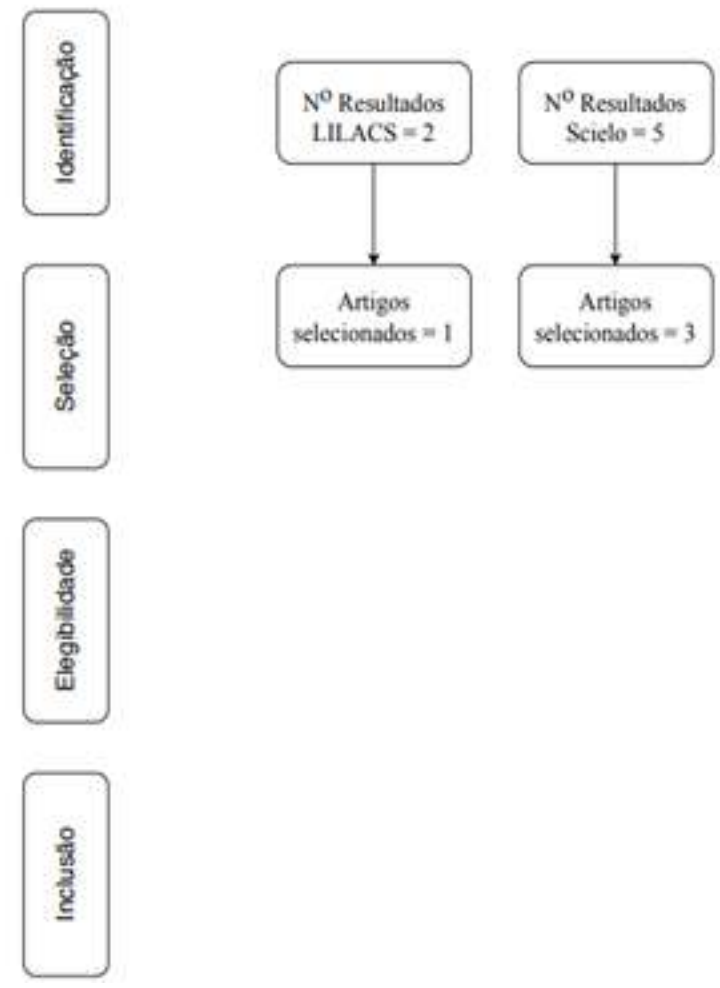

Os estudos selecionados foram recuperados na íntegra e lidos exaustivamente, extraindo dados mediante instrumento estruturado de fichamento, contendo informações sobre: título e revista, área de atuação dos autores, ano de publicação, local de realização do estudo, descritores, objetivo, método, sujeitos do estudo, principais resultados e recomendações/implicações. A partir do fichamento, os dados foram analisados de forma a descrever sucintamente o perfil das publicações, e categorizar qualitativamente os textos, dividindo-os em categorias temáticas que são descritas em função dos objetivos dos estudos, principais resultados e recomendações/implicações.

\section{RESULTADOS}

A maioria dos trabalhos era internacional $(n=10)$, tendo apenas dois trabalhos produzidos no Brasil. Os trabalhos nacionais foram realizados na região Sudeste do país, enquanto os trabalhos internacionais distribuíram-se pela América do Norte $(n=2)$, Ásia

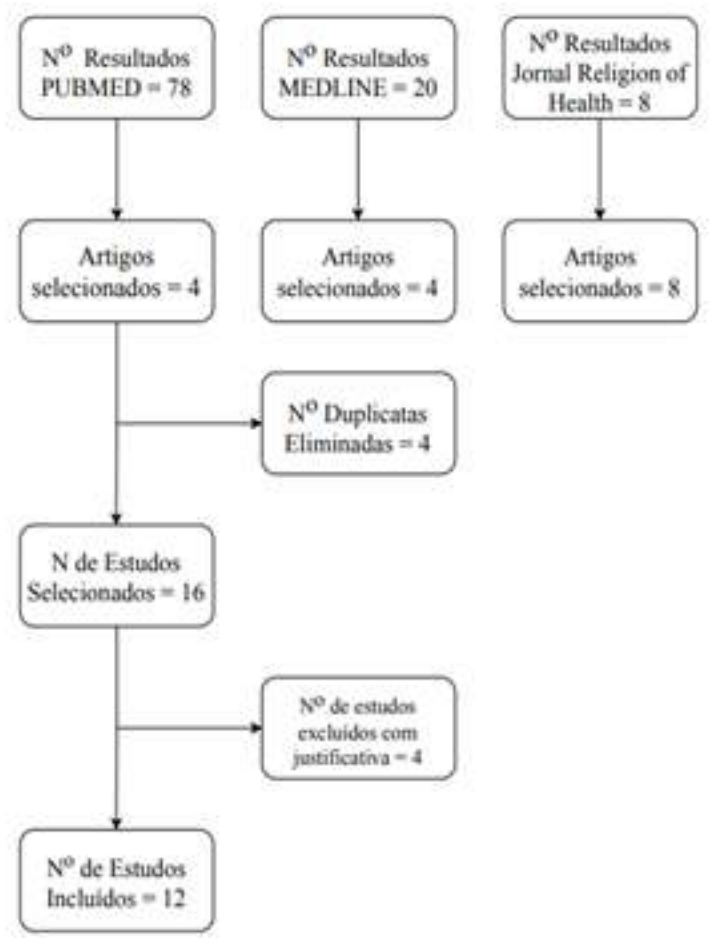

$(n=4)$, Europa $(n=2)$ e dois trabalhos foram realizados na Turquia, país situado entre o continente europeu e o asiático. A abordagem quantitativa é predominante $(83,3 \%, n=10)$, mas foram encontrados dois estudos qualitativos. A análise qualitativa dos conteúdos dos trabalhos permitiu a identificação de três categorias: 1) vivências e perspectivas espirituais sobre o processo de doação e transplante de órgãos; 2) influência da religião e espiritualidade na tomada de decisão diante do processo doação e transplante; 3) religião/ espiritualidade influenciando o paciente/cuidador na doença e no transplante.

\section{Vivências e perspectivas espirituais sobre o processo de doação e transplante de órgãos}

Os trabalhos elencados nessa categoria apresentam experiências de pacientes que vivenciaram a espiritualidade no processo de transplante de órgãos e a visão de estudantes e líderes religiosos sobre perspectivas espirituais do processo de doação e transplante de órgãos. 
Escrito por um capelão de um Centro Médico de Chicago, um estudo internacional apresenta uma narrativa detalhada que descreve a jornada psicológica, emocional e espiritual de um paciente em processo de transplante de fígado. ${ }^{13} \mathrm{~A}$ narrativa explorou desde a espera até a realização do transplante, revelando que nessa jornada, o paciente passou por estágios de crises, euforia e convenção, estabelecendo-se por último num estágio de senso de missão. O paciente desse estudo também relatou após o transplante a mudança de prioridades em sua vida, como considerar a família sempre em primeiro lugar, a transformação de sentimentos de mágoa em perdão, a aquisição da visão de um mundo melhor e a transformação de sua fé, pois se antes via-se abandonado por Deus, após o transplante passou a enxergá-lo mais em sua vida e em suas falas. Através do senso de missão adquirido, o paciente passou a promover uma vez por semana um grupo de suporte para pacientes e famílias que enfrentam o processo de transplante.

Estudo similar foi realizado na cidade de Gonbad Kavous, no Irã, que teve por objetivo investigar a relação entre a observação de crenças religiosas e o sofrimento observado em pacientes que fazem hemodiálise. ${ }^{14}$ Esse estudo contou com a participação de 130 pacientes de dois diferentes hospitais da cidade de Gonbad Kavous. Cada paciente recebeu dois questionários, um sobre as crenças religiosas, que foi desenvolvido baseado nas crenças islâmicas do Irã, e outro sobre o sofrimento durante a hemodiálise. Os resultados obtidos demonstraram que crer em uma prática religiosa reduz o sofrimento em pacientes que realizam hemodiálise. O trabalho discute ainda sobre o importante papel das crenças religiosas à adaptação da situação de doente e sua função como redutoras de dor e sofrimento.

Uma pesquisa realizada na Turquia mensurou o conhecimento de estudantes de enfermagem e de teologia sobre a doação de órgãos..$^{15} \mathrm{O}$ estudo selecionou essa amostra por acreditar que futuramente, ambas profissões irão desempenhar importante papel na conscientização da população sobre a importância da doação de órgãos. A pesquisa foi realizada na Universidade Firat, nas faculdades de Enfermagem e Teologia, e os estudantes receberam um questionário contendo questões sobre as atitudes diante da doação de órgãos, como "Você acha que a doação de órgãos é importante para a sociedade?", e "Você doaria um órgão para um familiar em caso de necessidade?". A última parte do questionário foi composta por uma escala de conhecimento sobre doação de órgãos e tecidos e transplantes. A pesquisa contou com 578 estudantes, sendo que $49.3 \%$ da amostra foi composta por estudantes de enfermagem e $50.7 \%$ por estudantes de teologia. Sobre as atitudes diante da doação de órgãos, $78,5 \%$ dos estudantes achavam que a doação é algo necessário para a humanidade e 95\% afirmaram que doariam um órgão para um familiar em caso de necessidade. Quanto ao desejo de ser um doador de órgão, as questões religiosas são mais importantes para os estudantes de teologia do que para os de enfermagem. Quanto à escala, o score dos estudantes de enfermagem foi maior que os dos estudantes de teologia.

Também na Turquia, um grupo de investigadores analisou a opinião de 40 oficiais religiosos da Estação Mufti, no distrito de Zeytinburnu, Istambul, sobre doação e transplante de órgãos. ${ }^{16}$ Os participantes foram submetidos a um questionário composto por questões do ponto de vista individual, e também da perspectiva islâmica a respeito da doação e transplante de órgãos.

Os resultados evidenciaram que pouco mais da metade da amostra $(52,5 \%)$ considerava seu conhecimento a respeito da doação e transplante de órgãos parcialmente adequado; a maior parte dos participantes relatou ter tido contato prévio com informações sobre o tema, inclusive $45 \%$ deles afirmaram ter adquirido informações através do Directorate of Religious Affairs, que é um diretório responsável por administrar as mesquitas e oficiais religiosos, e que organiza treinamentos através de convenções mensais; $92,5 \%$ dos participantes declararam que a religião islâmica é favorável à doação de órgãos; $55 \%$ dos pesquisados afirmaram que existe diferença entre as visões adotadas na Turquia e em outros países muçulmanos a respeito da doação de órgãos, e 55\% consideraram inadequado o conhecimento dos oficiais religiosos da Turquia sobre transplante e doação de órgãos.

\section{A influência da religião e espiritualidade na tomada de decisão diante do processo doação e transplante}

Os trabalhos aqui apresentados descrevem como e quanto a religião e espiritualidade influenciam na tomada de decisão diante do processo de doação e transplante de órgãos.

Um estudo qualitativo, realizado com 30 pacientes doadores voluntários (que não conheciam o futuro receptor) de rim, foi o primeiro a descrever como a religião e espiritualidade influenciam na experiência do processo de doação vivenciado por doadores não relacionados. ${ }^{17}$ Neste estudo, três temas específicos relacionados à religião e espiritualidade e à escolha de doar foram identificados: motivação para doar, processo durante o transplante e a experiência pós-transplante. 
A motivação para doar foi definida como fator influente de persuasão para se tornar um doador. As influências identificadas nessa fase foram: 1) participantes criados em um contexto religioso revelaram que sua exposição à espiritualidade e religiosidade contribuíram para a decisão de doar; 2) alguns dos participantes enxergaram a oportunidade da doação como um presente de Deus, ou como um sinal de terem sido escolhidos por Deus para ajudar o receptor; 3 ) os participantes entenderam sua doação como um meio de obter mérito ou então receberem ajuda para alcançar a vida após a morte, especialmente dois pacientes budistas.

Durante o processo de doação, a religião e espiritualidade foram consideradas fontes de suporte durante a jornada da doação. Os pacientes relataram ter sido através das crenças religiosas e do compromisso com atividades espirituais que superaram as preocupações associadas à doação e tranquilizaram-se sobre a escolha de doar.

A experiência pós-doação foi dividida em dois subtemas:

1) relação com o receptor: alguns participantes recorreram ao suporte da fé para conseguir interagir com os receptores do rim doado, pois não sabiam para quem o rim seria transplantado, até a doação terminar;

2) perspectivas da doação: os participantes sentiramse gratos por terem oportunidade de completar a doação com sucesso e por ajudarem o receptor de seu rim.

Uma pesquisa semelhante teve por objetivo explorar a contribuição da etnia, espiritualidade, nível de religiosidade e conhecimento das atividades do Centro Nacional de Transplantes de Israel - Israel National Transplant Center (INTC) - para construção das atitudes em relação à doação de órgãos entre judeus e árabes muçulmanos em Israel. ${ }^{18}$ Os resultados demonstraram que os judeus tiveram mais atitudes positivas em relação à doação de órgãos quando comparado aos árabes muçulmanos. Árabes muçulmanos apresentaram maior score de espiritualidade que os judeus.

Um notável estudo multicêntrico envolvendo a Áustria, República do Chipre, Alemanha e Suécia, países que eram participantes do projeto Chalenge of Biomedicine (CoB), visou discutir e determinar de qual maneira as percepções e convicções religiosas são usadas no momento da tomada de decisão frente à doação de órgãos, pesquisando-se em dois grupos diferentes. ${ }^{19} \mathrm{O}$ primeiro grupo foi composto por doadores e receptores de órgãos, assim como familiares próximos, e o segundo por pessoas que não eram doadoras ou receptoras, mas que estavam engajadas nos assuntos de transplante de órgãos. Pelos dados coletados, ficou claro que os argumentos religiosos apresentados foram utilizados tanto a favor quanto contra a doação e transplante de órgãos. Não houve consenso ou homogeneidade entre as conclusões das pessoas que tinham fé. A definição médica de morte cerebral foi o start de muitas conversas, e ainda foi um ponto muito contestado em diferentes religiões em questões como: do que uma pessoa é feita (corpo e alma) e onde a vida acaba.

Já um estudo realizado na Alemanha, publicado em 2019, objetivou analisar em que extensão as denominações religiosas e atitudes individuais influenciam, de fato, decisões que dizem respeito ao fim da vida, e quais as visões de certas religiões em relação à morte encefálica, ao transplante de órgãos e à autópsia. ${ }^{20}$

A amostra da pesquisa foi selecionada considerando pessoas que implementassem questões religiosas em suas vidas pessoais, os alvos sendo, portanto, estudantes de teologia e pessoas de comunidades religiosas, como igrejas, mesquitas e templos da cidade de Hesse, Alemanha, e algumas cidades vizinhas. Dos questionários distribuídos, 1306 foram respondidos, demonstrando os seguintes resultados notáveis: os participantes pertenciam, em sua maioria, às seguintes religiões: Judaísmo, Cristianismo (católicos, protestantes e ortodoxos), Islâmica (Xiitas e Sunitas), Hinduísmo e Budismo. Outra parcela dos participantes declarou não fazer parte de nenhuma religião.

Ainda no mesmo estudo, quando o assunto era morte encefálica, os participantes que eram judeus, acompanhados da maioria dos participantes protestantes e que denominaram não ter religião, determinaram que essa é considerada uma morte definitiva, enquanto em sua maioria, os participantes budistas, hinduístas e muçulmanos consideraram que essa não é uma morte definitiva. Sobre o transplante de órgãos: a doação de órgãos voluntária entre pacientes vivos foi apoiada por grande parte de todos os grupos religiosos; quando se trata da doação de órgãos de pessoa falecida, o transplante foi apoiado por católicos, protestantes, judeus e pessoas que não pertencem a qualquer uma dessas religiões.

O apoio à doação de órgãos foi maior quando questionado sobre doador vivo do que de doador já falecido, tendo a grande maioria dos participantes budistas, hinduístas e muçulmanos rejeitado a doação de órgãos após a morte encefálica. Sobre a autópsia: muitos participantes de todos os grupos religiosos assumiram que a autópsia interfere na paz e descanso pós-morte; apenas os não religiosos não pensavam dessa maneira. Como possíveis motivos para negar uma autópsia, encontraram-se: mutilação do corpo e postergação do velório. 


\section{Religião/espiritualidade influenciando o paciente/ cuidador na doença e no transplante}

A associação da religião e espiritualidade com qualidade de vida, bem-estar físico e espiritual de pacientes e cuidadores no contexto do transplante de órgãos também tem sido discutida na literatura.

Um estudo nacional propôs avaliar a qualidade de vida, religiosidade e sintomas da ansiedade e depressão nos candidatos a transplante de fígado. ${ }^{21}$ A pesquisa foi realizada com 50 pacientes submetidos à avaliação de aspectos clínicos, psicológicos, farmacêuticos, fisioterápicos e de enfermagem por meio de instrumentos preestabelecidos, que tinham por objetivo, dentre outras coisas, mensurar o envolvimento religioso relacionado a desfechos de saúde e avaliar a qualidade de vida dos pacientes. Os resultados obtidos indicaram que quanto maior a religiosidade não organizacional, melhor a função emocional e menor a preocupação dos pacientes com questões relacionadas ao transplante.

Já no Irã, um trabalho foi realizado tendo por objetivo determinar a efetividade da terapia espiritual no bemestar espiritual, na autoestima e autoeficácia em pacientes em hemodiálise. ${ }^{22} \mathrm{~A}$ pesquisa foi realizada com 24 pacientes em hemodiálise, que foram divididos em dois grupos de caso e controle. Os participantes foram submetidos a instrumentos que avaliam o bemestar espiritual, a autoestima e a autoeficácia e aqueles pertencentes ao grupo de experimento foram submetidos a consultas de terapia espiritual de 60 minutos cada, duas vezes por semana, durante seis semanas. O estudo obteve que após as seis semanas, as determinantes autoeficácia e autoestima apresentaram-se aumentadas no grupo experimental e permaneceu a mesma no grupo controle. A variável bem-estar espiritual aumentou após a intervenção no grupo experimental, e também levemente no grupo controle, mas os pesquisadores atribuíram essa relação com o pretexto da pesquisa.

Um terceiro trabalho analisado teve por objetivo avaliar a influência da espiritualidade na função renal de pacientes transplantados renais. ${ }^{23} \mathrm{O}$ estudo, que foi realizado no interior do estado de São Paulo, contou com a participação de 81 pacientes divididos em dois grupos: o grupo espiritualizado $(n=52)$ e o menos espiritualizado $(n=29)$. Buscou-se avaliar e comparar a evolução da função renal ao longo de 12 meses em ambos os grupos, através de coletas de dados realizadas aos três, seis, nove e doze meses após o início do estudo, mediante o uso de seis questionários validados. Entre os resultados obtidos, destacam-se os seguintes achados: em relação aos grupos, o espiritualizado apresentou clearance de creatinina significativamente maior a partir do nono mês ( $p=0,009$ ); ao fim de 12 meses, a percentagem de pacientes com clearance de creatinina superior a $60 \mathrm{ml} / \mathrm{min}$ foi de $61,5 \%$ no grupo espiritualizado e de $34,5 \%$ no grupo menos espiritualizado $(p=0,02)$; a análise multivariada de fatores de risco associados a apresentar clearance de creatinina inferior a $60 \mathrm{ml} / \mathrm{min}$ ao fim de 12 meses mostrou que pertencer ao grupo menos espiritualizado associou-se a um risco 4,7 vezes $[1,4-16,8]$ maior para piora da função renal $(p=0,01)$. Quanto aos desfechos secundários, a perda do enxerto foi zero no grupo espiritualizado e $6,9 \%$ no grupo menos espiritualizado $(p=0,12)$.

O último trabalho atribuído a essa categoria possui um público alvo distinto dos estudos apresentados anteriormente, pois analisou a relação do bemestar espiritual com a sobrecarga de cuidadores de pacientes em hemodiálise. ${ }^{24} \mathrm{~A}$ pesquisa realizada no Irã contou com a participação de 382 cuidadores de pacientes em hemodiálise, que foram submetidos a três questionários, sendo um composto por questões sociodemográficas, um sobre bem-estar espiritual e um sobre registro de carga do cuidador. Dentre os resultados obtidos, ressalta-se o achado de que o bem-estar espiritual desempenha importante papel em reduzir a sobrecarga dos cuidadores de pacientes que fazem hemodiálise.

\section{DISCUSSÃO}

A religião e a espiritualidade são constructos que recebem cada vez mais ênfase na assistência à saúde, na medida em que são comumente percebidos como forma de atribuir sentido à vida, de ter esperança e estar em paz em meio a acontecimentos graves, como no processo de adoecimento. ${ }^{25}$ Atualmente, evidenciam-se associações entre maior religiosidade ou espiritualidade dos pacientes e maior bem-estar geral em casos de doenças mentais; ${ }^{26}$ menor prevalência de depressão, ${ }^{27}$ abuso de drogas ${ }^{28}$ e suicídio; ${ }^{29}$ melhor qualidade de vida:30-32 modo mais adequado de lidar com a doença (coping), ${ }^{33}$ menor mortalidade; ${ }^{34-35}$ menos tempo de internação ${ }^{36} \mathrm{e}$, até mesmo melhor função imunológica. ${ }^{37}$

É notável o corpo consistente de trabalhos científicos já desenvolvidos nessa área, mas percebe-se um tímido envolvimento do Brasil, merecendo nossa atenção imediata. Uma vez que temos atingido números significativos de doações e transplantes de órgãos sólidos no país, é imprescindível que o avanço tecnológico seja acompanhado de discussões acerca do papel que a religião e espiritualidade exercem em experiências como essa. 
Nos estudos analisados nesta pesquisa, religião e espiritualidade demonstraram desempenhar importante papel na adaptação à situação do doente e como redutoras de dor e sofrimento, além de estarem presentes durante a jornada do transplante. Estudos nacionais que investigaram o uso da religião e espiritualidade em pacientes oncológicos demonstraram resultados semelhantes, com ambas assumindo importante papel no enfrentamento do tratamento quimioterápico, auxiliando na compreensão da qualidade de vida e a lidar com os cuidados paliativos, e também como estratégia para diminuição da ansiedade. ${ }^{38-40}$ Outros estudos nacionais, que pesquisaram a religião e espiritualidade em pacientes dialíticos demonstraram que o nível de religião e espiritualidade está correlacionado com o nível de felicidade, além de correlacionar-se positivamente com crenças de esperança e otimismo. ${ }^{41-42}$

Esses estudos, juntamente com os estudos analisados nesta pesquisa, levam a concluir que religião e espiritualidade estão presentes em situações adversas de saúde, mas embora existentes, ainda são poucos trabalhos nacionais que abordam a espiritualidade e religiosidade nesse contexto.

Os estudos analisados por este trabalho também abordaram diferentes contextos de ensino, tanto no âmbito teológico como da saúde,${ }^{15}$ além de investigações envolvendo líderes religiosos. ${ }^{16}$ Tanto os alunos de enfermagem, quanto os de teologia foram escolhidos, por se acreditar que desempenharão importante papel futuramente na conscientização da população a respeito da doação e transplante de órgãos, e a escolha por oficiais religiosos justificou-se por motivo semelhante, visto que a visão negativa ou positiva dos religiosos sobre doação de órgãos influencia o público de sua religião. Na literatura nacional foi possível encontrar artigos explorando o conhecimento dos estudantes da área da saúde a respeito da doação e transplante de órgãos, ${ }^{43-46}$ com justificativas semelhantes às do estudo analisado nesta pesquisa, mas não foram encontrados artigos que investigassem o conhecimento dos alunos de teologia.

A religiosidade e espiritualidade, consideradas componentes da vida do homem, possuem grande poder de influência tanto nos diferentes contextos da vida como nas interações sociais, culturais e na dimensão psicológica, as quais são demonstradas pelos valores, crenças, comportamentos e emoções. ${ }^{47} \mathrm{~A}$ religiosidade costuma oferecer diretrizes para o comportamento do homem, motivando ou induzindo-o a tomar decisões e posicionamentos de acordo com suas crenças e valores religiosos, desde as escolhas básicas do dia a dia até as escolhas mais complexas. Muitos estudos demonstram essa influência, como aqueles que apresentam a religião e espiritualidade motivando pacientes a lutarem contra a dependência de substâncias psicoativas, ${ }^{48}$ contra a ansiedade, ${ }^{49}$ e outros que demonstram a influência da religiosidade sobre a escolha das vestes femininas, ${ }^{50}$ sobre o aborto ou sobre a eutanásia. ${ }^{51}$

Os dados encontrados nesta revisão reiteram a influência da religião e espiritualidade na tomada de decisão diante do processo de doação e transplante de órgãos, revelando que a religião influenciou tanto na doação, quanto na não doação de órgãos e quais as crenças que levaram a tal decisão. Evidencia-se a importância de saber quais as crenças que levam a optar pela não doação de órgãos, uma vez que um estudo nacional já demonstrou que a religiosidade corresponde a $19 \%$ das causas de recusa familiar à doação de órgãos e tecidos. ${ }^{52}$

Quanto aos trabalhos que apresentaram a religião/ espiritualidade como influência no paciente/cuidador na doença e no transplante, eles evidenciaram a associação entre religião e espiritualidade com qualidade de vida, bem-estar físico e espiritual de pacientes e cuidadores no contexto do transplante de órgãos.

O período prolongado na fila de espera exerce impactos significativos na vida do paciente quanto ao seu bemestar, probabilidade cura, natureza e extensão das sequelas, bem como na vida dos familiares envolvidos, e também na sociedade. Os pacientes que estão à espera de um transplante enfrentam sentimentos como tristeza pela doença, sofrimento, revolta, sentimentos de fragilidade e ansiedade; sentimentos negativos relacionados às múltiplas mudanças ocorridas na vida, tais como: inutilidade, impotência, desconforto, perda, desilusão, vergonha, insatisfação e labilidade emocional,6 sentimentos esses que impactam negativamente na qualidade de vida do paciente.

Estudos nacionais afirmam que a qualidade e vida dos pacientes em hemodiálise apresenta-se baixa nos domínios físico e psicológico, ${ }^{53-54}$ mas também revelam que a religiosidade é uma fonte de conforto e esperança para os pacientes com Insuficiência Renal Crônica, promovendo bem-estar geral e que se correlaciona positivamente com uma satisfação com a qualidade de vida.

\section{CONCLUSÃO}

A presente revisão possibilitou sintetizar o conhecimento disponível sobre religião e espiritualidade no contexto dos transplantes, resultando em três categorias: 
1) vivências e perspectivas espirituais sobre o processo de doação e transplante de órgãos; 2) influência da religião e espiritualidade na tomada de decisão diante do processo doação e transplante; 3) religião/ espiritualidade influenciando o paciente/cuidador na doença e no transplante.

A pesquisa também possibilitou notar que embora a religião e espiritualidade desempenhem papéis muito importantes na vida do paciente no contexto do transplante, o tema ainda é pouco abordado e pouco trabalhado principalmente no âmbito nacional, o que reforça a importância de se produzir mais pesquisas com esse enfoque, visto que a religião e a espiritualidade têm potencial de influenciar e interferir na qualidade de vida desses pacientes.

Esperamos, portanto, que a partir do levantamento desses conhecimentos já existentes, novos caminhos de pesquisa possam ser traçados, bem como novas recomendações para a prática clínica, posto que a investigação realizada nesta revisão demonstrou a religião e a espiritualidade como fortes fatores que influenciam a vivência, a qualidade de vida e a tomada de decisão de pacientes que estão no processo de doação e transplante de órgãos.

\section{ABSTRACT}

Purpose: To investigate scientific production regarding religion and spirituality in the context of solid organ transplantation. Methods: Integrative literature review was performed on the MEDLINE, LILACS and PUBMED databases, in the Scielo library and in the Journal of Religion and Health, by primary articles published in Portuguese, English or Spanish. Data were collected by using a file instrument and qualitatively analyzed. Results: 12 articles were selected and described in three categories: Experiences and spiritual perspectives on the organ donation and transplantation process; influence of the religion and spirituality in making a decision regarding the donation and transplantation process; religion / spirituality influencing the patient / caregiver in the disease and in the transplant. Conclusion: The available literature has indicated that religion and spirituality are factors influencing patients in multiple ways in this context and requiring further investigation.

Keywords: Transplantation; Tissue Donors; Religion, Spirituality.

\section{REFERÊNCIAS}

1. Mendes KDS, Roza BA, Barbosa SFF, Schirmer J, Galvão CM. Transplante de órgãos e tecidos: responsabilidades do enfermeiro. Texto contexto - enferm. 2012;21(4):945-53. doi: 10.1590/ S0104-07072012000400027.

2. Campos HH. Aumento do número de transplantes e da doação de órgãos e tecidos: processo de construção coletiva [Internet]. São Paulo: Associação Brasileira de Transplante de Órgãos; 2001. [citado em: 2019 out 19]. Disponível em: http://ww.abto.org. $\mathrm{br} /$ profissionais/ biblioteca/textos_transplante1.htm

3. Lima AAF. Doação de órgãos para transplante: conflitos éticos na percepção do profissional. São Paulo: O Mundo da Saúde [Internet]; 2012 [acesso em: 2019 out 19];36(1):27-33. Disponível em: http://bvsms.saude.gov.br/bvs/artigos/mundo_saude/doacao_orgaos_transplante_conflitos_eticos.pdf

4. Marinho A. A situação dos transplantes de órgãos no Brasil. Instituto de Pesquisa econômica Aplicada. Brasília; 2009 [acesso em: 2020 jun 22]. Disponível em: http://repositorio.ipea.gov.br/ bitstream/11058/1564/1/TD_1389.pdf
5. Melo GB, Aguiar AKB, Melo GB, Silva VMS, Albuquerque MCS, Brêda MZ. Os sentimentos das pessoas que aguardam por um órgão ou tecido na fila única de Transplante [Internet]. J Bras Transpl. 2012[acesso em 2019 out 19];15(3):1661-69. Disponível em: https://www.researchgate. net/publication/274509288_Os_sentimentos_das_pessoas_que_aguardam_por_um_orgao_ou_tecido_na_fila_unica_de_Transplante

6. Park CL, Masters KS, Salsman JM, Wachhooltz A, Clements $A D$, Salmoirago-Blotcher A, et al. Advancing our understanding of religion and spirituality in the context of behavioral medicine. J Behav Med [Internet]. 2017 [cited: 2019 Oct 24];40(1):39-51. Available from: http://link. springer. com/article/10.1007\%2Fs10865-016-9755-5

7. Richardson P. Spirituality, religion and palliative care. Ann Palliat Med. [Internet] 2014 [cited: 2019 Oct 24];3(3):1509. Available from: http://apm. amegroups.com/article/ view/4175/5049 
8. Balboni TA, Vanderwerker LC, Block SD, Paulk ME, Lathan CS, Pettet JR, et al. Religiousness and spiritual support among advanced cancer patients and associations with end-of-life treatment preferences and quality of life. J Clin Oncol. 2007;25(5):555-60. doi: 10.1200/JCO.2006.07.9046.

9. Travado L, Grassi L, Gil F, Martins C, Ventura C, Birradas J; Southern European Psycho-Oncology Study Group. Do spirituality and faith make a difference? Report from the Southern European Psycho-Oncology Study Group. Palliative Supportive Care. 2010;8(4):405-13. doi: 10.1017/S147895151000026X

10. Silva CF, Borges FR, Avelino CCV, Miarelli AVTC, Vieira GIA, Goyatá SLT. Spirituality and religiosity in patients with systemic arterial hypertension. Rev Bioét. 2016;24(2):332-43. doi: 10.1590/1983-80422016242134

11. Nunes MGS, Leal MCC, Marques APO, Mendonça SS. Long-lived elderly: assessment of quality of life in the field of spirituality, religiousness and personal beliefs. Saúde debate [Internet]. 2017;41(115 ):1102-15. doi: 10.1590/01031104201711509 .

12. Santos NC, Abdala GA. Religiosity and health-related quality of life of elderly in a city in Bahia, Brazil. Rev bras geriatr gerontol. 2014;17(4):795-805. doi: 10.1590/18099823.2014.13166.

13. Shuford RW. The spiritual journey of an organ transplant patient. J Pastoral Care Counsel. 2003;57(2),191-6. doi: https:// doi.org/10.1177/154230500305700209

14. Okhli A, Hojjati H, Sadeghloo A, Molaei A, Shahrabady S. The relationship between observing religious beliefs and sufering in hemodialysis patients. J Relig Health. 2019. doi: https:// doi.org/10.1007/s10943-019-00887-7

15. Soylar P, Ulaş Kadioğlu B. Theology and nursing students' knowledge of organ donation and transplantation. Transplant Proc. 2018;50(10):2961-2965. doi:10.1016/j.transproceed.2018.09.011

16. Tarhan M, Dalar L, Yildirimoglu H, Sayar A, Altin S. The view of religious officials on organ donation and transplantation in the Zeytinburnu District of Istanbul. J Relig Health. 2015;54(6):1975-85. doi: 10.1007/s10943-014-9851-1

17. Maghen A, Vargas GB, Connor SE, Nassiri S, Hicks EM, Kwan L, et al. Spirituality and religiosity of non-directed (altruistic) living kidney donors. J Clin Nurs. 2018;27(7-8):166272. doi:10.1111/jocn.14223

18. Melnikov S, Ashkenazi T, Amara M, Peles Bortz A. Transcendental spirituality and acquaintance with the activities of the domestic national transplant center as factors shaping attitudes toward organ donation. Prog Transplant. 2017;27(2):13945. doi:10.1177/1526924817699967

19. Röcklinsberg $\mathrm{H}$. The complex use of religion in decisions on organ transplantation. J Relig Health. 2009;48(1),62-78. doi: 1007/s10943-008-9209-7

20. Alhawari Y, Verhoff MA, Ackermann H, Parzeller M. Religious denomination influencing attitudes towards brain death, organ transplantation and autopsy-a survey among people of different religions. Int J Legal Med. 2020;134(3):1203-1212. doi:10.1007/s00414-019-02130-0
21. Paglione HB, Oliveira PC, Mucci S, Roza BA, Schirmer J. Qualidade de vida, religiosidade e sintomas ansiosos e depressivos em candidatos a transplante hepático. Rev esc enferm USP. 2019;53:e03459. doi:10.1590/s1980-220x2018010203459.

22. Darvishi A, Otaghi M, Mami S. The Effectiveness of spiritual therapy on spiritual well-being, self-esteem and self-efficacy in patients on hemodialysis. J Relig Health. 2020;59(1):277-88. doi:10.1007/s10943-018-00750-1

23. Bravin AM, TretteneAS, Cavalcante RS, Banin VB, Paula NAMR, Saranholi TL, et al . Influência da espiritualidade sobre a função renal em pacientes transplantados renais. Acta paul enferm. 2017;30(5):50411. doi: 10.1590/1982-0194201700073.

24. Rafati F, Mashayekhi F, Dastyar N. Caregiver burden and spiritual well-being in caregivers of hemodialysis patients. J Relig Health. 2019;10.1007/s10943-019-00939-y. doi:10.1007/ s10943-019-00939-y

25. Davison SN, Jhangri GS. Existential and supportive care needs among patients with chronic kidney disease. J Pain Symptom Manage. 2010;40(6):838-43. doi: 10.1016/j.jpainsymman.2010.03.015

26. Kirby SE, Coleman PG, Daley D. Spirituality and well-being in frail and non frail older adults. J Gerontol B Psychol Sci Soc Sci. 2004;59(3):P123-9. doi: 10.1093/geronb/59.3.p123

27. Smith TB, McCullough ME, Poll J. Religiousness and depression: evidence for a main effect and the moderating influence of stressful life events. Psychol Bull. 2003;129(4):614-36. doi: 10.1037/0033-2909.129.4.614.

28. Kendler KS, Liu XQ, Gardner CO, McCullough ME, Larson D, Prescott CA. Dimensions of religiosity and their relationship to lifetime psychiatric and substance use disorders. Am J Psychiatry. 2003;160(3):496-503. doi: 10.1176/appi.ajp.160.3.496.

29. Almeida AM, Lotufo Neto F. Religião e comportamento suicida. In: Meleiro AM, Teng CT, Wang YP, organizadores. Suicídio: estudos fundamentais. São Paulo: Segmento Farma; 2004;53-60.

30. Floriano PJ, Dalgalarrondo P. Saúde mental, qualidade de vida e religião em idosos de um Programa de Saúde da Família. J Bras Psiquiatr. 2007 [acesso em: 2020 Jun 22];56(3):62-170. Disponível em: https://www.scielo.br/scielo.php?pid=S0047$-20852007000300002 \&$ script=sci_abstract\&tIng=pt

31. Peterman AH, Fitchett G, Brady MJ, Hernandez L, Cella D. Measuring spiritual well-being in people with cancer: the functional assessment of chronic illness therapy-spiritual well-being Scale (FACIT-Sp). Ann Behav Med. 2002;24(1):49-58. doi: 10.1207/S15324796ABM2401_06

32. Panzini RG, Rocha NS, Bandeira DR, Fleck MPA. Qualidade de vida e espiritualidade. Rev Psiq Clín. 2007;34(Supl1):10515. doi: 10.1590/S0101-60832007000700014

33. Narayanasamy A. Spiritual coping mechanisms in chronic illness: a qualitative study. J Clin Nurs. 2004;13(1):116-7. doi: 10.1046/j.1365-2702.2003.00834.x

34. Seeman TE, Kaplan GA, Knudsen L, Cohen R, Guralnik J. Social network ties and mortality among the elderly in the Alameda County Study. Am J Epidemiol. 1987;126(4):714-23. doi: 10.1093/oxfordjournals.aje.a114711 
35. Oman D, Reed D. Religion and mortality among the community-dwelling elderly. Am J Public Health. 1998;88(10):1469-75. doi: 10.2105/ajph.88.10.1469

36. Koenig HG, Larson DB, Hays JC, Mc Cullough ME, George LK, Branch PS et al. Religion and survival of 1,010 male veterans hospitalized with medical illness. J Relig Health. 1998 [cited: 2020 Jun 22];37(1):15-29. Available from: https://link.springer.com/article/10.1023/A:1022904915837

37. Koenig HG, Cohen HJ, George LK, Hays JC, Larson DB, Blazer DG. Attendance at religious services, interleukin-6, and other biological indicators of immune function in older adults. Int J Psychiatry Med. 1997;27(3):233-50. doi: 10.2190/40NF-Q9Y2-0GG7-4WH6

38. Mesquita AC, Chaves Érika CL, Avelino CAV, Nogueira DA, Panzini RG, Carvalho EC. A utilização do enfrentamento religioso/espiritual por pacientes com câncer em tratamento quimioterápico. Rev. Latino-Am. Enfermagem [Internet]. 2013;21(2):539-545. doi: 10.1590/S010411692013000200010.

39. Matos TDS, Meneguin S, Ferreira MLS, Miot HA. Quality of life and religious-spiritual coping in palliative cancer care patients. Rev. Latino-Am Enfermagem [Internet]. 2017;25:e2910. doi: 10.1590/1518-8345.1857.2910.

40. Carvalho CC, Chaves ECL, lunes DH, Simão TP, Grasselli CSM, Braga CG. Effectiveness of prayer in reducing anxiety in cancer patients. Rev esc enferm USP [Internet]. 2014;48(4):684-90. doi: 10.1590/S0080623420140000400016.

41. Siqueira J, Fernandes NM, Moreira-Almeida A. Association between religiosity and happiness in patients with chronic kidney disease on hemodialysis. J Bras Nefrol. 2019;41(1):22-8. doi:10.1590/2175-8239-jbn-2018-0096.

42. Gomes ICC, Manzini CSS, Ottaviani AC, Moraes BIP, Lanzotti RB, Orlandi FS. Attitudes facing pain and the spirituality of chronic renal patients in hemodialysis. BrJP [Internet]. 2018;1(4): 320-4. doi: 10.5935/2595-0118.20180061.

43. Galvao FHF, Caires RA, Azevedo-Neto RS, Mory EK, Figueira ERR, Otsuzi TS, et al . Conhecimento e opinião de estudantes de medicina sobre doação e transplante de órgãos. Rev Assoc Med Bras. 2007;53(5): 401-6. doi: 10.1590/S0104-42302007000500015.
44. Reis FP, Gomes BHP, Pimenta LL, Etzel A. Brain death and tissue and organ transplantation: the understanding of medical students. Rev bras ter intensiva. 2013;25(4):279-83. doi: 10.5935/0103-507X.20130048.

45. 3046. Freire ILS, Dantas BAS, Gomes ATL, Silva MF, Mendonça AEO, Torres GV. Aspectos éticos e legais da doação de órgãos: visão dos estudantes de enfermagem. R Enferm Cent O Min. 2015;5(2):1594-603. doi: 10.19175

47. Henning-Geronasso MC, Moré CLO. The influence of religiousness/spirituality in the psychotherapeutic context. Psicol cienc prof. 2015;35(3),711-25. doi: 10.1590/19823703000942014.

48. Zerbetto SR, Gonçalves AMS, Santile N, Galera SAF, Acorinte AC, Giovannetti G. Religiosity and spirituality: mechanisms of positive influence on the life and treatment of alcoholics. Esc Anna Nery. 2017; 21(1): e20170005. doi: 10.5935/1414-8145.20170005

49. Ribeiro LCJM, Balestra AG, Nicoletti EA, Donadon MF. A espiritualidade na flexibilização de pensamentos e crenças de uma paciente ansiosa. Rev Bras ter cogn. 2019;15(2), 126-131. doi: 10.5935/1808-5687.20190018

50. Rigoni ACC, Prodócimo E. Corpo e religião: marcas da educação evangélica no corpo feminino. Rev Bras Ciênc Esporte. 2013;35(1):227-43. doi: 10.1590/S010132892013000100017.

51. Gomes EC, Menezes RA. Aborto e eutanásia: dilemas contemporâneos sobre os limites da vida. Physis [Internet]. 2008;18(1):77-103. doi:10.1590/S0103-73312008000100006.

52. Pessoa JLE, Schirmer J, Roza BA. Evaluation of the causes for family refusal to donate organs and tissue. Acta paul enferm. 2013;26(4):323-30. doi: 10.1590/S010321002013000400005

53. Takemoto AY, Okubo P, Bedendo J, Carreira L. Avaliação da qualidade de vida em idosos submetidos ao tratamento hemodialítico. Rev Gaúcha Enferm. (Online) . 2011;32(2): 256-62. doi: 10.1590/S1983-14472011000200007.

54. Jesus NM, Souza GF, Mendes-Rodrigues C, Almeida NOP, Rodrigues DDM, Cunha CM. Quality of life of individuals with chronic kidney disease on dialysis. J Bras Nefrol. 2019;41(3):364-74. doi: 10.1590/2175-8239-jbn-2018-0152.

\section{AGRADECIMENTO}

Agradecemos ao Programa Institucional de Bolsas de Iniciação Científica, PIBIC/ CNPQ. 